transit time. In patients with formed stools (scores 1-4) and normal or slow transit frequent defecation and urgency are actually pseudodiarrhoea, presumably due to an irritable or hyperreactive rectum, and constipating agents should be avoided. As patients with slow and fast transit may respond differently to high fibre diets and bulking agents, respectively, perhaps they should be asked to record their stool form so that the doctor can assess the transit rate and plan treatment.
1 Rao SSC, Holdsworth CD, Read NW. Symptoms and stool patterns in patients with ulcerative colitis. Gut 1988;29:342-5.

Cummings JH, Wiggins HS. Transit through the gut measured by analysis of a single stool. Gut 1976;17:219-23.

Metcalfe AM, Phillips SF, Zinsmeister AR, MacCarthy RL, Beart RW, Wolff BG. Simplified assessment of segmental colonic transit. Gastroenterology 1987;92:40-7.

4 Davies GJ, Crowder M, Reid B, Dickerson JWT. Bowel function measurements of individuals with different eating patterns. Gut 1986;27:164-9.

5 Manning AP, Thompson WG, Heaton KW, Morris AF. Towards positive diagnosis of the irritable bowel. Br Med F 1978;ii:653-4.

(Accepted 17 October 1989)

\section{Anxiety caused by abnormal result of cervical smear test: a controlled trial}

\author{
Clare Wilkinson, Jane M Jones, Jenny McBride
}

Department of General Practice, University of Wales College of Medicine, Cardiff CF3 7PN Clare Wilkinson, MRCGP, lecturer

\section{South Glamorgan Health Authority, Cervical Cytology Clinic, St David's Hospital, Cardiff CF1 9TZ Jane $M$ Jones, FRCOG, director of the cervical cytology programme}

\section{Department of Clinical Psychology, University Hospital of Wales, Cardiff CF4 4XW \\ Jenny McBride, DIPCLINPSYCH,} senior clinical psychologist

Correspondence to: Dr C Wilkinson, Llanedeyrn Health Centre, Maelfa, Cardiff CF3 7PN.
Cervical intraepithelial neoplasia is common in young symptomless women. Such women often believe that the function of a smear test is to detect cancer rather than to prevent it. ${ }^{1}$ Insensitive postal notification of abnormal results can cause unnecessary fear and add to the negative aspects of a mass screening programme. ${ }^{23}$

We carried out a controlled trial to assess women's anxiety and beliefs about their health when a smear test showed dyskaryosis and to evaluate the effectiveness of a personal leaflet sent with postal notification of the result of such a test.

\section{Patients, methods, and results}

Women due to attend the University Hospital of Wales because a cervical smear test had shown dyskaryosis were randomly assigned to one of two groups. The first group (31 patients) received a standard computerised letter, which read: "Your recent smear test showed slight abnormality. Please could you attend the cytology clinic at...for a repeat test and further advice." The second group (29 patients) received a leaflet and a more personalised letter stating, "Your recent smear test showed slight abnormality which need cause you no anxiety. Please read the enclosed leaflet carefully, you will find it helpful and reassuring. Please could you attend the cytology clinic at ... on. ..." The main message in the leaflet was that most smears showing dyskaryosis do not indicate cervical cancer. All patients were interviewed during the consultation by the examining doctor $(\mathrm{CW})$, who used a structured questionnaire. Information collected comprised sociodemographic data, psychiatric history, the women's perceptions of the meaning of the result of their smear test, and their perceptions of their health after receiving the result. They were asked who they had chosen to discuss the result with and whether they had sought professional advice before their appointment. Differences between the two groups were measured by comparing the women's beliefs about their health as measured by the questionnaire and their levels of anxiety before and after consultation as assessed with the Speilberger state-trait anxiety inventory. ${ }^{+}$

Nineteen women who did not receive a leaflet thought that they had cancer compared with only one of the women who did receive a leaflet $\left(\chi^{2}=22 \cdot 56, \mathrm{df}=\right.$ $1, p<0.001)$. Twelve of the women not sent a leaflet thought that their health had deteriorated on receipt of the result compared with two who were sent a leaflet $(\mathrm{p}<0.01$; Wilcoxon matched pairs signed ranks test).
The group who were not sent a leaflet had a significantly higher initial state anxiety level than the group who were $(\mathrm{p}<0.0001)$. State anxiety levels after consultation and trait anxiety levels were not significantly different between the groups (table).

Anxiety scores of patients who had received letter, with or without reassuring leaflet, informing them that cervical smear test showed dyskaryosis

\begin{tabular}{lccc}
\hline $\begin{array}{c}\text { Mean Speilberger } \\
\text { state-trait inventory } \\
\text { scores (scale 20-80) }\end{array}$ & $\begin{array}{c}\text { Group not } \\
\text { sent leaflet } \\
(\mathrm{n}=31)\end{array}$ & $\begin{array}{c}\text { Group } \\
\text { sent leaflet } \\
(\mathrm{n}=29)\end{array}$ & $\begin{array}{c}\text { Difference between } \\
\text { means }(95 \% \\
\text { confidence interval) }\end{array}$ \\
\hline State anxiety levels: & & & \\
Before consultation & 49.59 & $39 \cdot 00$ & $10.59(5 \cdot 8$ to $14 \cdot 8)$ \\
After consultation & 33.35 & 32.21 & $1.14(-3.4$ to $5 \cdot 7)$ \\
Trait anxiety levelf & 40.81 & 37.21 & $3.60(-7.6$ to 0.4$)$
\end{tabular}

* State anxiety is a measure of transitory emotional state characterised by subjective feelings of tension and heightened autonomic nervous system activity.

+ Trait anxiety is a measure of relatively stable individual differences in anxiety proneness.

\section{Comment}

Our study highlights the fact that precancer is a concept that women find difficult to understand. The term implies early cancer to most women, and a new term-for example, "early warning cells"-would seem more appropriate. The mean level of anxiety before consultation in the women not sent a leaflet was similar to that provoked by very stressful situations, while the mean in the group sent a leaflet was similar to that expected for general medical and surgical outpatients. ${ }^{5}$

Evidence suggests that investigation and treatment of cervical intraepithelial neoplasia is psychologically traumatic. ${ }^{5}$ Good education and counselling from the onset may prevent future psychiatric and psychological morbidity and improve compliance with treatment. A questionnaire sent to all health authorities in Wales in September 1988 showed that, although seven of nine health authorities sent educational leaflets with cervical cytology call and recall letters, only one sent leaflets when notifying women of normal or abnormal results of smear tests. Our study suggests that these leaflets should be sent with notification of abnormal results.

We thank Professor Nigel Stott and Dr Roisin Pill, department of general practice, University of Wales College of Medicine, and Dr Tim Peters, department of medical statistics, University Hospital of Wales, for help with design and analysis; Mrs Penny Moore for typing the manuscript; and Pfizer for financial help.

\footnotetext{
1 Eardley A. Attendance for cervical screening-whose problem? Soc Sci Med 1985;20:955-62.

2 McCormick J. Cervical smears: a questionable practice? Lancet 1989;ii:207-9. 3 Marteau T. Psychological costs of screening. Br Med f 1989;299:527.

4 Speilberger C. Manual for the state-trait anxiety inventory. California: Consulting Psychor C. Manual for the sic

5 Posner T, Vessey M. Prevention of cervical cancer-the woman's view. Oxford: Nuffield Provincial Hospitals Trust, 1988.

(Accepted 29 November 1989)
} 